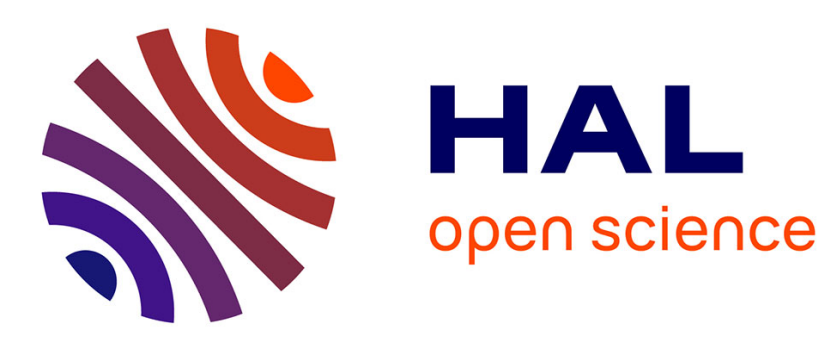

\title{
INTEGRATION OF SUBORBITAL SPACEFLIGHT AT A COMMERCIAL AIRPORT IN FRANCE
}

\author{
Jérôme Crevatin, Garrett Smith
}

\section{To cite this version:}

Jérôme Crevatin, Garrett Smith. INTEGRATION OF SUBORBITAL SPACEFLIGHT AT A COMMERCIAL AIRPORT IN FRANCE. IAC 2015, 66th International Astronautical Congress, IAF, Oct 2015, Jerusalem, Israel. hal-01270365

\section{HAL Id: hal-01270365 \\ https://hal-enac.archives-ouvertes.fr/hal-01270365}

Submitted on 7 Feb 2016

HAL is a multi-disciplinary open access archive for the deposit and dissemination of scientific research documents, whether they are published or not. The documents may come from teaching and research institutions in France or abroad, or from public or private research centers.
L'archive ouverte pluridisciplinaire HAL, est destinée au dépôt et à la diffusion de documents scientifiques de niveau recherche, publiés ou non, émanant des établissements d'enseignement et de recherche français ou étrangers, des laboratoires publics ou privés. 


\title{
IAC-15,D6,3,2,x29879
}

\section{INTEGRATION OF SUBORBITAL SPACEFLIGHT AT A COMMERCIAL AIRPORT IN FRANCE}

\author{
Jérôme Crevatin \\ Ecole Nationale de 1'Aviation Civile, Toulouse, France, jerome.crevatin@eleve.enac.fr \\ Endowment Fund "Destination Etoiles", France \\ Garrett Smith \\ Cosmica Spacelines, Colomiers, France, garrett.smith@cosmicaspacelines.com
}

This paper investigates a preliminary evaluation of the suitability of airports in France for reusable suborbital spaceflight operations. The authors propose a methodology and tool to easily perform preliminary spaceport site evaluation, which considers runway length \& surface, local weather conditions, existing air \& ground traffic, and safety for the uninvolved public. All of these have consequences on site selection for a spaceport.

The authors briefly present the potential legal framework for suborbital flights in France with the objective of finding an acceptable regulatory framework. Due to the absence of explicit requirements, the U.S. regulations established by the FAA-AST have been used as a guideline to frame the scope of the investigations.

A methodology has been developed and a weighting established for various criteria to rate any selected airport. Matlab and $\mathrm{C}$ scripts were authored to automate data intensive aspects of the analysis. A simplified aerodynamic model for two representative space planes were developed to provide trajectory data for nominal and nonnominal flight. Data tables were created through manual entry and automated databases extraction to provide the input for the overall analysis.

This paper shows a case study of the airport in Montpellier, France, with a flight path directly over the Mediterranean sea. The overall study shows that several airports in France are acceptable and justify further investigations regarding their feasibility.

\section{INTRODUCTION}

Commercial suborbital spaceflight is rapidly developing in the United States, with initial operations foreseen within the next few years. After a successful introduction in the U.S. operators will be looking to expand abroad. Unfortunately, commercial operations in Europe, a promising market, might be hindered due to the lack of technical and regulatory preparations in this field in Europe.

France has always been a major actor in space history. The French national space agency, CNES, is recognized around the world for launching the ATV to the ISS on Ariane 5 for example, and the French military (DGA) for launching missiles. Before the selection of Kourou, the CNES studied the south-easterly facing Mediterranean coastline in the Languedoc region to build their launch site. These examples underline the fact that France has always been present for space activities for operations and innovation.

Suborbital spaceflight has many special characteristics: very high vertical speeds during the climb, potentially explosive propellants, glide approach and unpowered landing. All of these make suborbital flights very different from traditional aviation operations and often lead to conflicting needs for airport utilisation.

The authors believe that these conflicts can be appropriately managed and thus are investigating existing airports in France to identify preferred locations. Use of an existing airport also has the benefit of reducing costs associated with runway and terminal development for a green field project.

This study was originally conducted during an engineering internship for the main author, under the technical guidance of the co-author, and hosted by the Destination Etoiles foundation with financing by DLA Piper. The overall ranking of the French airports remains confidential and proprietary to the internship hosts although the aggregate analysis in this paper gives some insight into the promising nature of several airports.

\section{SCOPE OF WORK}

A very pragmatic approach was taken to limit the scope of research to the main areas of interest 
for integrating suborbital spaceflight into airport operations in order to ensure the work could be completed within the timeframe of the internship. Due to the very broad domains of potential investigation, the authors chose to concentrate on the essential technical characteristics as illustrated in Figure 1. The regulatory environment served as a boundary for the investigation by providing key parameters to satisfy.

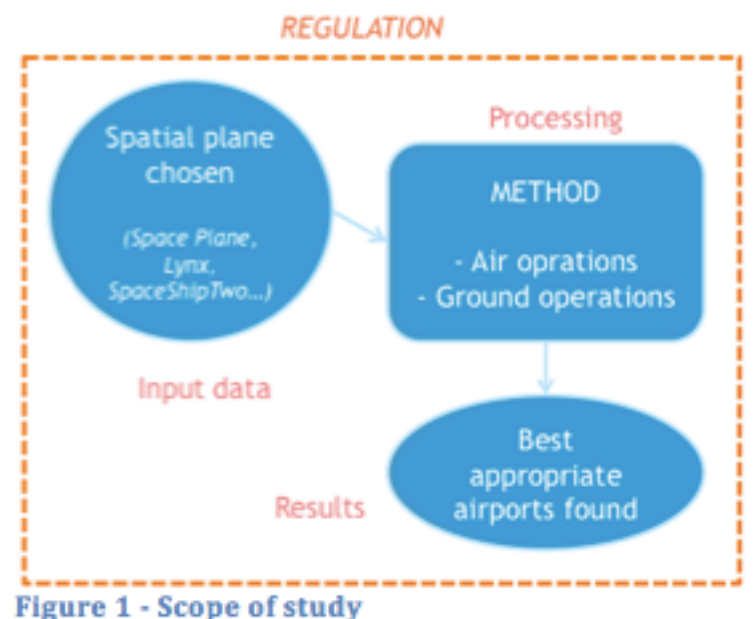

Environmental impacts such as pollution, noise or wildlife were ignored for this study even though the authors acknowledge that they are an essential element in the choice of an appropriate spaceport.

The key objective was to develop a tool to support the application of the method. After choosing a space plane, this software tool is able to rank the airports for suborbital flight operations. The tool could be adapted to rank airports in other countries with additional data.

\section{REGULATORY FRAMEWORK}

In Europe, there is no harmonized regulation similar to FAA-AST (Federal Aviation Administration, Office of Commercial Space Transportation) regulations for suborbital spaceflight. Smith argues that harmonization of activities is not foreseen in Europe for spaceflight operations due to the Treaty on the Functioning of the European Union and that even if suborbital operations are considered aviation activities, then this remains a national competence. ${ }^{[1]}$

Thus the authors briefly reviewed the French legal situation. The key question to ask is whether this is a space or an aviation activity to identify which French authority to approach. Unfortunately, this question has not yet been answered so both potential regulatory frameworks are briefly presented including their drawbacks.

\section{DGAC Sensational Flights Law}

In France, a decree has been adopted concerning the "Vols à Sensations" (thrill seeking flights). The ministry decree dated on the $8^{\text {th }}$ February of 2012 , has been adopted to set a legal framework on the use of the "Airbus ZeroG", operating parabolic flights to reproduce microgravity environment during few seconds and for high performance jet trainer aircraft. This legal framework could be applied to suborbital flights. Unfortunately, the law states that a "Titre de Navigabilité" (title of navigability) must be provided to the DGAC for the flight operations application. Unfortunately, it appears that an FAA-AST launch license does not qualify as a title of navigability. ${ }^{[2]}$

The law text states that the flight must be operated from a point $\mathrm{A}$ to $\mathrm{A}$, and applies to any aircraft operations which are publicly advertised. A safety analysis must be conducted, concerning people on the ground and other aircraft in case of non-nominal events.

\section{French Space Operations Law}

This "Loi des Operations Spatial" (LOS) $\mathrm{n}^{\circ}$ 2008-518 dated 3 June 2008 is used for launch vehicle and satellite operations, notably for Ariane 5, Soyuz and Vega launches from Kourou in French Guiana. The competent authority in France is the CNES.

This regulation provides a clear legal framework but there are no explicit requirements which operators need to meet. Every operation must prepare an application including safety management and CNES will review it on a case-bycase basis. This law provides requirements for insurance guarantees and the split of responsibility between the operator and the state. It also ensures the safety of the uninvolved public and compliance with international obligations.

Space planes can also be used as launchers and must respect in this case the Space Operations Law. Nevertheless, human spaceflights are specifically excluded from this regulation, which currently 
precludes use of this framework for pilots or passengers on suborbital vehicles.

\section{$\underline{\text { Developments in International Cooperation }}$}

The FAA and CNES have signed a Memorandum of Cooperation (MOC) on 16 June 2015 to cooperate on research and development related to the safety of private sector orbital space launches and re-entry activities. Unfortunately suborbital spaceflight is explicitly excluded from the scope of the memorandum. Fortunately for suborbital operators interested in France, the joint press release issued by the FAA and CNES stated that the MOC "...could pave the way for development of future arrangements between the FAA and France related to the regulation of suborbital reusable vehicles...". [3]

\section{IV.DEVELOPMENT OF THE METHOD}

The study focuses on technical aspects only, meaning that economical purposes such as market research is not evaluated in the method.

Three major factors are analyzed for airport evaluation as shown in Figure 2. First of all, the technical characteristics of the airport must respect spaceplane operational constraints: the runway length or its type of surface. Moreover, an analysis has to be conducted to ensure the safety of people on the ground in case of incident. That part takes into account the population density around the airport. The last criterion but not the least, is the integration in the current air and ground traffic. That part ensures the best cohabitation between air and space operations.

Additional factors have to be studied. The airport safety is a relevant element of the method. It analyzes and ensures the safety of travellers in

\section{TRAJECTORY DEFINING}

SAFETY ANALYSIS

TRAFFIC INTEGRATION

\section{ADDITIONAL CRITERIA}

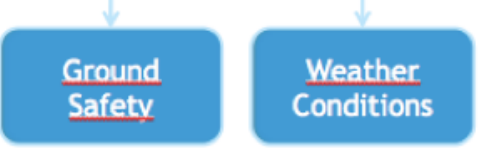

Figure 2 - Parts of the method commercial terminals of the airport but also airport employees and people living in the airport's neighbourhood. The weather is also a fundamental criterion that must not be under-estimated. If the sky is cloudy all year, suborbital activities could not be operated as frequently as operators would like.

All these criteria and how they are analyzed are detailed in following parts.

\section{How to rank airports ?}

In addition to evaluating the possibility to use an airport or not for suborbital activity, the method has to rank the best-selected airports. Each criterion will be graded and this grade has a weight.

Then, the weighted average is computed to make the overall ranking. To be included in the ranking, airports should respect minimum requirements. For example, if any trajectory is found to ensure the safety of habitants on the ground, the airport is eliminated. In the opposite, a too-short runway for operational use could be ranked, but receives a low grade due to the construction needed to extend the runway.

There are 4 sub-grades, one for each category. The coefficients and weights for each grade have been defined to represent the importance of each factor and the consequences. But this is a subjective evaluation with the aim to make a ranking. If the analysis is made with the same coefficients and weights, the result is credible due to the tendency.

\section{Method's goals}

The method is a "pre-selection". For this reason, the approach is global and may be studied deeper in each parts for an airport-focused study. The method has been reviewed by experts in their domains who approve the approach while acknowledging the shortcomings requiring further study. The final objective is to show that suborbital flights have the potential to be operated in France with all the safety constraints without building a dedicated spaceport.

\section{TRAJECTORY DETERMINATION}

The first step is to define the nominal path for the space plane. Trajectory is calculated from flight equations. The goal is to compute all the information that will be needed for the following parts of the study. Along the trajectory, flight data 
including speed, climb angle, position and mass are computed for each time step.

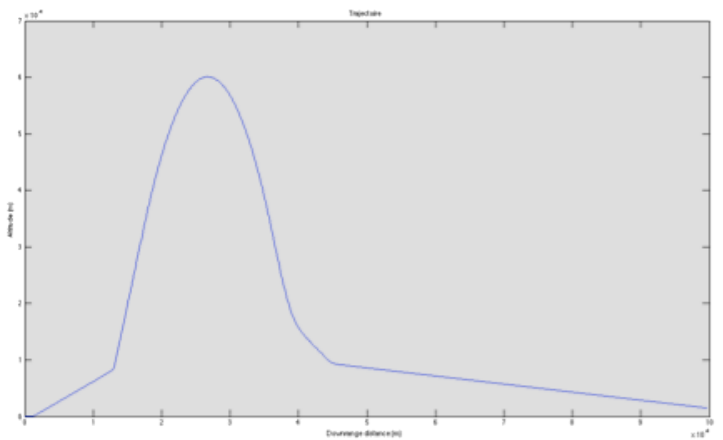

Figure 3 - Flight path

\section{Computing the trajectory}

The flight trajectory is firstly defined in two dimensions (Figure 3), computed in the plane: altitude versus downrange. The flight could be divided in five phases, detailed below. For each phases of the flight, aerodynamic equations are written. The lift equation [1] and the thrust equation [2] deal with aerodynamic purposes. Mass equation is added [3] and both position equations [4 and 5]. All equations issued are extracted from "Flight Mechanics" course given by G. Hattenberger (ENAC) and "Spaceflight Dynamics" course book written by William E. Wiesel [4][5]. Some assumptions are made for this computation. The specific impulse is considered constant in the simplified approach. Other assumptions are made: the angle of attack is assumed constant and defined for each phase of the flight, a friction force is added for the take-off to model the interaction between the runway and wheels.

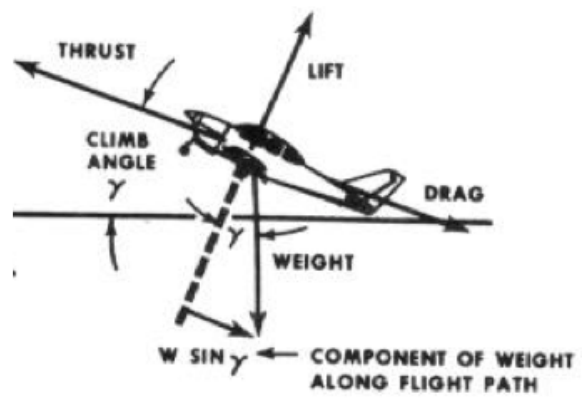

Figure 4 - Aerodynamic forces (www.astop.com)

Equations :

$m V \frac{d \gamma}{d t}=L-m g \times \cos (\gamma)$

where $L=\frac{1}{2} \rho(z) S V^{2} C_{L}$ with : - $m$ is the mass of the spacecraft,

- Vits speed,

- $g$ is the gravitational constant

$\left(g=9,81 \mathrm{~m} . \mathrm{s}^{-2}\right)$,

- $\gamma$ is the climb angle,

- $S$ is the lifting area,

- $\rho$ is the air density, function of

altitude,

- $C_{L}$ is the lift coefficient,

$m \frac{d V}{d t}=T-D-m g \times \sin (\gamma)$

[2]

where: $\begin{aligned} T & =I s p \times g \\ D & =\frac{1}{2} \rho(z) S V^{2} C_{D}\end{aligned}$

where: - Isp is the specific impulse,

- $C_{D}$ is the drag coefficient,

$$
\frac{d m}{d t}=-\beta
$$

where $\beta$ is the constant mass flow.

$$
\begin{aligned}
& \frac{d x}{d t}=V \times \cos (\gamma) \\
& \frac{d y}{d t}=V \times \sin (\gamma)
\end{aligned}
$$

To compute this differential system, external data are needed like air density, $C_{L}$ and $C_{D}$, which is function of $\mathrm{z}$, the altitude. To calculate air density, the standard atmosphere table is used. The software used to compute the trajectory is Matlab.

The different phases along the flight are detailed below:

\section{$\underline{0-\text { Take-off }\left(\mathrm{t}_{0}->\mathrm{t}_{1}\right)}$}

During take off, the contact of the wheels in the ground adds an extra force on the spacecraft. This is modelled by a friction force, which is proportionally inverted to the speed.

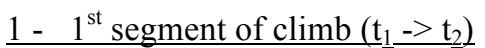

During the first phase, the climb angle is constant and equals to $\gamma_{1}$. The value of this climb angle depends on the aircraft. It is an input data. In this phase, the space plane accelerates. 


\section{$\underline{2-2^{\text {nd }}}$ segment of climb $\left(\mathrm{t}_{2}->\mathrm{t}_{\underline{b}}\right)$}

The climb angle is still constant and equals this time to $\gamma_{2}$ (with $\gamma_{2}$ higher than $\gamma_{1}$ ). The value of this climb angle depends also of the aircraft. The plane continues to accelerate until the end of the combustion.

\section{$\underline{3-\text { Ballistic shot }\left(\mathrm{t}_{\mathrm{b}}->\mathrm{t}_{\mathrm{g}}\right)}$}

At $t_{b}$, the engines power off. At this altitude, there is effectively no atmospheric drag. The trajectory is a ballistic path. The space plane continues the climb until reaching the apogee. Then, the descent starts and the spacecraft accelerates freely. With the reentry in atmosphere, the space plane slows down to reach the descent angle.

\section{4 - Glided phase $\left(\mathrm{t}_{\mathrm{g}}->\mathrm{t}_{\text {end }}\right)$}

At $t_{g}$, the plane continues its descent with a fixed constant descent angle $\gamma_{\mathrm{d}}$. The plane decelerates.

The trajectory is computed to a point near the airport at a certain altitude. Then, the plane circles to the airport.

Some space planes are air launched from an airplane. In this case, the take-off phase is not computed and the flight is analyzed from the dropped altitude with the first segment of climb.

Data computed with the previous explanations create a straight line in the downrange direction, varying only in altitude. Then, a 180-degrees turn is added to make the trajectory go back to the airport. In the method, one turn is allowed after the take-off to avoid populated area. This turn is automatically computed in the following part (non nominal study) to find the best trajectory as a function of population density. The trajectory is now in three dimensions.

\section{Converting of the trajectory}

The trajectory has been defined by solving differential equations. The output is a list of points, in a local frame. The points defining the trajectory must be converted in a global coordinate system. The LLA (Latitude, Longitude, Altitude) system is chosen with the reference WGS84, used for GPS systems.

For a dropped spacecraft, the dropping airplane can reach a precise and desired position but the operator cannot choose a point by chance. In an operational point of view and for safety reasons, the operator must take into account two important

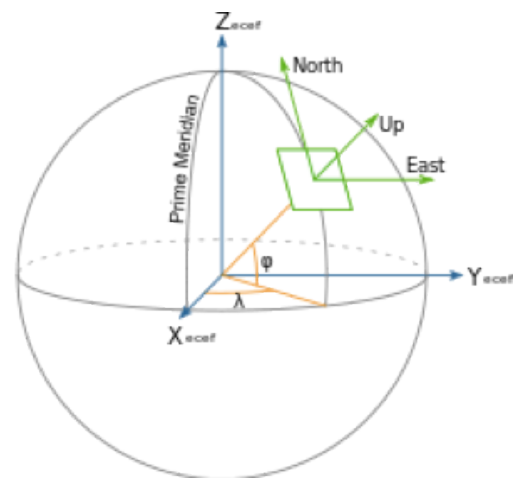

Figure 5 - Different frames

things: in case of ignition failure just after the drop, the space plane must be able to reach an airport, gliding, and the second one is that the space plane must be able to come back at the launching airport after apogee. The first condition is not analyzed in the tool but it is part of the method and must be checked manually. The second one is checked by the tool. The trajectory is oriented to the airport when re-entry has been made. Then the altitude over the airport is checked if it is high enough or not to accept the trajectory.

Results are stored in excel files. At this time, data can be used to visualize the trajectory and can be used for the following studies: non-nominal flight and traffic integration.

\section{Visualizing of the trajectory}

The idea is to visualize clearly the trajectory in GIS software such as Google Earth. A file readable by this kind of software (extension . $\mathrm{kml}$ ) is written with the Matlab code. The trajectory can be seen in the software, starting at the airport to the apogee, before coming back to the airport (Figure 6).

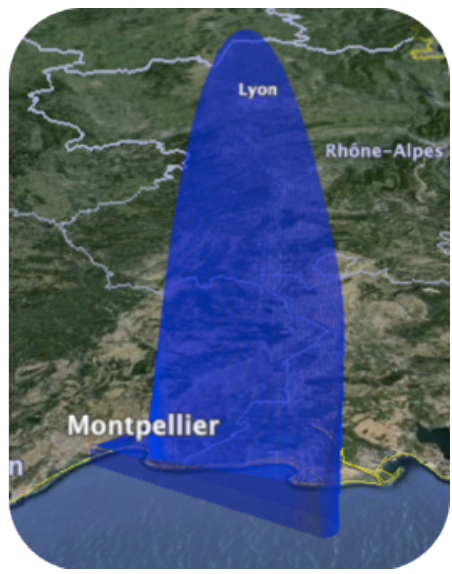

Figure 6 - Horizontal autonomous take-off spaceplane trajectory at Montpellier 


\section{Re-entry}

The re-entry is a critical part of the flight path. Spaceplane behaviours during this phase are not really easy to predict.

First of all, the theory from the re-entry aerodynamics is needed to compute the flight path. Then, the trajectory is drawn and defined in function of the performances parameters of the space plane (speed, angle of attack) and also the position around its gravity centre.

The re-entry must be taken into account for the non-nominal part because it is a critical part of the flight, but for the trajectory, the impacted elliptical area defined in the next part already takes into account a non nominal event during this phase.

\section{NON-NOMINAL STUDY}

The purpose of this part is to ensure the safety of people on the ground. First, failure probabilities are defined using existing data on space and air operations to evaluate the acceptable risk level. Then, the computation of debris impact is done to be compared with population density.

\section{Analysis description}

First, the probability of having a power loss is defined. The value is around $1 \%$, uniformly distributed on combustion time.

In reality, this probability is little higher at the beginning of the flight, after ignition but to simplify calculations, it is ignored. The plane glides back to the airport or proceeds to an emergency landing in a non-populated area minimizing injuries for people on board and on the ground if the plane remains usable.

Two different cases appear when the plane is unusable: dislocation or explosion. The worst case is the explosion due to the energy released during the explosion giving relative speeds to debris causing a high dispersion of debris on the ground. Both cases are considered significant for the safety ground study and plane dislocation is included in the explosion case. This is conservative. Unusable plane case appears every 1.000 launches, regarding Figure $7 . \mathrm{P}_{\text {flight }}$ is equals to $10^{-3}{ }^{[6]}$

Moreover, the probability $\mathrm{P}_{2}$ is the one to kill at least one person knowing that a non-nominal event

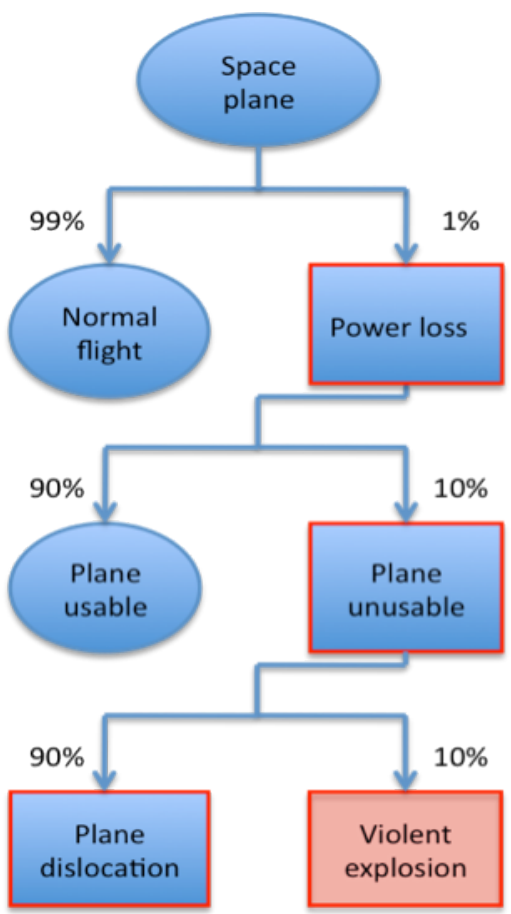

Figure 7 - Flight failures (CNES, C. Bonnal)

happened at instant $t$. It has to be computed all along the propelled phase. It is characterized by the Casualty Expectation $\left(\mathrm{E}_{\mathrm{C}}\right)$ [7] :

$$
E(i, j)=P(i, j) \times N_{j} \times \frac{A_{c, i}}{S_{j}}
$$

where :

- $P(i, j)$ is the probability that the debris $i$ hits the cell $j$,

- $N_{j}$ is the number of habitants in the cell $j$,

- $A_{c, i}$ is the impacted surface of debris $i$ (Casualty Area),

- $S_{j}$ is the surface of cell $j$.

The difficulty of this method is to define $P(i, j)$. This probability is usually found running a MonteCarlo simulation. For a first approach, it is reasonable to simplify the method aiming to reduce computing time during the analysis. For a second run, the Monte-Carlo has to be chosen.

\section{Simplified method}

The simplification deletes the Monte-Carlo simulation. At an instant $t$, the explosion is simulated. The energy delivered by the explosion is function of the remaining fuel mass. In fact, the energy "E" is proportional to the TNT equivalent mass (given in kilograms) of the fuel and propellants remaining at the moment of the explosion defined in Joules in the Equation [7]. 


$$
E=4.184 \times 10^{6} \cdot m_{e q, T N T}
$$

To compute the equivalent TNT mass, the chart given by the FAA-AST ${ }^{[7]}$ is used. Many assumptions are made. The energy received by all debris is the same. The explosion energy is not fully converted to kinetic energy. Only $50 \%$ of the energy is transmitted as a blast, remaining energy for thermal and radiation [8]. But the debris doesn't go as fast as the blast. In the end, it is assumed that $10 \%$ of the initial energy is transmitted to the debris. Then the relative speed for a debris can be found with equation [8].

$$
v_{i, \text { relative }}=\sqrt{\frac{2 E_{k}}{m_{i}}}
$$

where:

- $E_{k}$ : kinetic energy for one debris which is equals to the total kinetic energy divided by the number of debris

- $m_{i}$ : mass of debris $i$

To compute debris trajectories, only few extreme debris are analyzed to increase computing performances. Debris are modelled around the space plane gravity centre. The computation uses the same equations described in part IV for aerodynamics and impacts on the ground can be found. Two assumptions are made: debris do not bounce on the ground and people protection due to buildings is not taken into account. An elliptic zone is modelled around the impact points and converted in the LLA system. This elliptic area is named $\mathrm{S}_{\mathrm{t}}$. The sum of all the elliptic areas $S_{t}$ gives the $S$ area, which can be visualized in Google Earth (Figure 8).

The Casualty Area $\left(A_{C}\right)$ is estimated for each space plane. This is the total surface covered by all the debris increased by 36 centimetres. It is really difficult to estimate this value which depends on the number of pieces constituting the plane. The fuselage surface is estimated with available data and wings surfaces are known. Inside pieces has to be added, such as seats, computers, tanks. But the Casualty Area depends also with the numbers of debris.

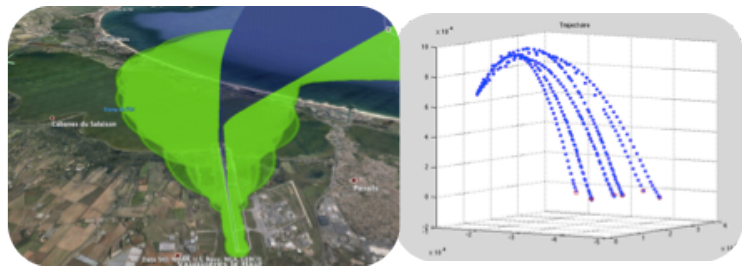

Figure 8 - $\mathrm{S}$ area visualization and debris impact modeling
Knowing the LLA coordinates of S, the number of people living in the area can be found. The national database is used. The mesh is composed of 200-meters-side-squares. The coordinate system used is the LAEA Europe - ESPG3035 based on ETRS89. It is a $(\mathrm{x}, \mathrm{y})$ system, using meters. The coordinates of surface $\mathrm{S}$ have to be converted in this system and the number $\mathrm{N}$ of habitants in the area can be found.

The number to evaluate is equal to $\left(\mathrm{N}^{*} \mathrm{~A}_{\mathrm{C}}\right) / \mathrm{S}$ (equation [9]). This is the number of person reached $\left(\mathrm{N}_{\mathrm{R}}(t)\right)$ by debris, for one simulation (at a given instant $\mathrm{t}$ ).

$$
N_{R}(t)=\frac{N \times A_{C}}{S}
$$

A limit must not be crossed. A test is realized at each instant $t$ along the propelled phase. This limit must respect the safety probability for space, characterised by $\mathrm{E}_{\mathrm{C}, \operatorname{MAX}}{ }^{[7]}: \mathbf{E}_{\mathrm{C}, \mathbf{M A X}}=\mathbf{3 0 . 1 0 ^ { - 6 }}$.

Previously, it has been shown that the probability that a catastrophic event happens $\left(\mathrm{P}_{\text {flight }}\right)$ is equals to $10^{-3}$. $\mathrm{E}_{\mathrm{C}}$ can be written, in equation [10]:

$$
E_{C}=P_{\text {flight }} \cdot \bar{N}_{R}
$$

This equation gives us a maximum of $\bar{N}_{R, \max }=30.10^{-3}$ for the average of $\mathrm{N}_{\mathrm{R}}$. To know if a trajectory is acceptable or not, the average of $\mathrm{N}_{R}$ ( $\bar{N}_{R \text {,max }}$ ) must be computed for the whole combustion phase. The value can be so high that it is a waste of time to simulate during all the combustion phase. A test is made to gain time. The mean is computed for each instant $\mathrm{t} \quad\left(=\bar{N}_{R}(t)\right)$, assuming that during the whole remaining combustion time, nobody is reached by debris.

If $\bar{N}_{R}(t)<\bar{N}_{R \text {, max }}$, the test is valid and the study can begin for the next time step. If not, this trajectory cannot be accepted. This process is explained in the following part.

\section{Trajectory Optimization}

If the risk exceeds the limit, the initial trajectory must be defined again including turns to avoid the highly-populated area. If all the solutions had been tested and the population criteria never reached, the airport is not usable for suborbital flights. The process tests at each instant $t$ if a non-nominal event 
consequences are acceptable or not, regarding the population impacted. A one-second non-nominal time-step is a good compromise between computing time and accuracy of the study. The analysis is based on the data computed for the trajectory.

The program computes in this case a new trajectory including a turn before the instant $t$ where the probability was too high. The default value is 20 degrees. The program computes alternatively a new trajectory to the right and then to the left of the original trajectory. If a complete U-turn has been realized and the test is still accepted, the airport is eliminated. Analyzed data are stored in a file to show the number of habitants, the surface impacted and the probability, for each time step.

\section{Operational point of view}

The non-nominal study analyzes both take-off directions for departure. It means that two nominal trajectories have to be found for horizontal $\mathrm{T} / \mathrm{O}$ planes. If a trajectory is accepted for one take-off direction only, then the airport should not be penalized due to possible downwind $\mathrm{T} / \mathrm{O}$.

\section{Re-entry}

The re-entry is one of the most critical points during a suborbital flight. The consequences are high temperatures and pressures on the plane. Suborbital planes re-entry is quite different due to the relatively low speed of the vehicle around Mach 4 ; it was Mach 25 for the Space Shuttle.

Anyway, the re-entry should be taken into account in the $\mathrm{P}_{\text {flight }}$. For safety reason, the re-entry has consequences on plane flying above the space plane if an explosion or dislocation occurs. The process is detailed in the next part.

\section{TRAFFIC INTEGRATION}

This part deals with the integration of suborbital flights in current air traffic. Vertical and high velocity manoeuvres of those spacecraft make the integration difficult. The actual way to manage the ATC is more horizontal and the air traffic controller is not used with vertical path around Mach 3. A process must be established to ensure safety during the spaceplane's ascent and descent.

\section{VII.I Operational issues}

Most of space planes have emptied their tanks before reaching the apogee and will not be able to perform a go around in case of missed approach or, in case of extraordinary closure of the airfield. Some spacecrafts have a special engine system which can be re-ignited and let the plane perform one go-around to integrate again the circuit for a last landing. This imposes one statement: the runway must be closed from the moment that the space plane takes-off until its landing has been completed. The commercial traffic is impacted during the runway closure.

\section{Alternatives can be considered: \\ - Two (or more) parallel runways in the airport. One runway can remain opened. But, the probability that the two runways may be closed at the same time has to be analyzed.}

- An alternate airport could be chosen. It has to be clearly defined for each airfield. From the take-off until a decision point, the alternate airport is closed, or at least one runway is closed. At the decision point, the pilot of the space plane chooses the regular or the alternate airport. The one chosen is closed, or at least one runway, until the landing completed. The other one can be opened.

- For dropped space plane, the closing time of the "rescue airport" and "final airport" runways is the dropping time.

The method has to analyze the impact of a runway closure. Airports with a low number of movements per day are the most appropriate to operate suborbital spaceflights.

VII.II Avoiding en-route airplanes during climbing and gliding phases

Cruising airplanes follow routes or airways, materialized by virtual points. The major part of commercial planes movements can be known using the airways positions. But some planes don't really follow those airways due to ATC needs to avoid collision or direct-route trajectories. The selection of an airport must take into account the airways above and around the runways. The idea is to find a vertical corridor, wide enough to ensure the safety of operations but impacting as little as possible the air traffic. This corridor must include the fact that a non nominal flight can occur and the debris impact zone has to be taken into account.

A no-cross zone is defined relative to the trajectory. The number of airplanes and the frequency crossing this zone is analyzed. A database composed of all flights routes for one 
typical day has been created with the help of different CRNA (French Air Traffic Control Centres).

The zone envelope takes into account the trajectory of the spacecraft but also the trajectories of debris in case of incident. The zone is activated during all the propelled time and remains closed until the re-entry has been completely done, at least. The number of airplanes crossing the virtual zone and their crossing time can be found and analyzed. If the zone is activated, those planes should modify their route to avoid it under the orders of ATC. The less aircrafts diverted, the best is for suborbital activity for airport selection.

If the ascent phase is complicated due to the high speed of the vehicle, the way back is not so simple. The plane goes slower, but without any propulsion system, meaning that it is restricted regarding altitude changes. When it approaches again the altitude around 15 kilometres, the air traffic control must be in contact with the pilot to manage the situation with other aircrafts.

\section{VII.III Ground traffic impact}

Commercial planes and general aviation use also taxiways and runways. As mentioned in part A, the eventuality of the runway closing has to be taken into account. To quantify the impact on commercial operations, the number of aircraft movements can be a relevant indicator ${ }^{[9]}$.

The very restrictive consequences of ground traffic in comparison of air traffic should be shown in the grading. The air traffic can be diverted and the time spent to do this little change on their route is around the minute. But on the ground, when suborbital operations start, planes wait in the air or on the ground but there is not other solutions, except if there is an other runway.

\section{ADDITIONAL CRITERIA}

\section{VIII.I Airport characteristics : runway length and strength}

This criterion links space planes performances and airport characteristics, especially runway length and strength. The take-off run is evaluated during the trajectory modelling. But one thing has to be considered : an engine failure shortly after take-off. Even if the non nominal study takes into account the population density, this part of the method is more for the safety of people inside the space plane.

\section{Runway length}

If the space plane has a total engine failure, it can glide. But it has to be at a certain altitude to come back and align on the runway to perform an unpowered landing. The distance computed takes into account the critical point at the limit where the space plane cannot perform the manoeuvre described just before. From this critical point, the space plane glides to the runway but keeping the take-off axis and can land safely. For a horizontal take-off spaceplane, the needed distance is evaluated at 2600 meters. Under this value, the runway must be extended and the grade is lower for the ranking.

For an air launched space plane, the needed distance is the one necessary for the carrying plane to take-off with the space plane attached on or under it. This distance is estimated around 3000 meters.

\section{Runway strength - ACN/PCN}

Runway strength is never a limiting parameter. The relative small weights of the space planes do not impose restrictions on this criterion.

\section{VIII.II Ground safety study}

Commercial airplanes burn kerosene when spaceplanes use propellant mixes such as liquid oxygen (LOX) and RP-1 (fuel), or liquid hydrogen for example. This implies that safety distances between public and spacecrafts must be defined and respected. Precise processes during refuelling or in case of LOX leak have to be established.

\section{Safety distances}

Three things are considered if an explosion happens: the pressure wave, the heat wave and the debris dispersion. The distance needed is directly taken from the regulation, proportional to the NEW (Net Equivalent Weight). The American legislation defined by the FAA-AST was taken into account for the study. To analyze if an airport is ready to welcome such machines, distances between any point where the space plane is susceptible to be and commercial terminals, roads or maintenance and servicing buildings must be analyzed. This study requires a huge database for airport buildings. The choice that has been made is to draw the exclusion zone. Then, it is possible to visualize it on GoogleEarth or GeoPortail with the building database. 


\section{Special processes}

Due to the fact that space planes could evolve near commercial aircraft, some special processes must be defined. In the exclusion zone, it is necessary that nobody except the tow pilot is present. Lighters, cigarettes, telephones, electricity systems, or any objects which could provoke spark are excluded from the exclusion zone. During refuelling, the operation must be done over concrete even if the airport pavement is made of asphalt. A special concrete area must be built. During taxiing, the doors are unlocked and "passengers" unattached until the power on.

One of the most critical event and not usual for commercial aviation is a liquid oxygen (LOX) spill. According to the studies ${ }^{[10][11]}$, one conducted by the NASA, the cohabitation of LOX and asphalt could be explosive in the opposite of the concrete and LOX contact where nothing happen. A surveillance system for LOX spill must be built. For this reason, non-concrete runways are penalized in the grading for LOX-use planes.

\section{VIII.III Local weather conditions}

Space planes operate under VFR conditions, meaning that the pilot uses his eyes to control the plane and is not allowed to go through clouds. In fact, the local weather conditions must be favourable to ensure that operations can be done as many days as possible. The unique constraint is the impossibility to go through the clouds. Meaning that a partially cloudy sky can be reasonable to fly. The rain is not a constraint directly to operate or not the flight, but will increase the needed runway length for landing.

The method analyzes three major weather factors. The first one is the rain, the second is the period of sunshine and then, the wind. For each factor, a mean value is taken into account but also the number of days regarding special events. For example, the first value for sunshine level is the average sunshine in hours per year. The second factor is the number of days where the sunshine is lower than $20 \%$. It means that this day, a suborbital activity is probably not possible. Due to gliding approach and unpowered landing, it is better to have also lower winds and the most regular as possible, meaning that gusts are not appreciated.
VIII.III USING THE TOOL AND ANALYZING RESULTS

\section{Airport selection and data}

Due to the very selective criterion of nonnominal flight density limit, it was not necessary to study all the airports in France. The position of each thresholds and runway orientation had been stored in the data file using Google Earth tools for selected airports. The runway length and width have been taken from the SIA (Aeronautical Information Service). Airports too far from the wanted criterion have been directly eliminated. Airports with long runways, near a low-populated area and a lowtraffic density have been chosen where the weather conditions fitted well with suborbital operations. The following airports have been evaluated :

1. Ajaccio Napoléon-Bonaparte,

2. Bastia Poretta,

3. Béziers Cap d'Agde,

4. Bordeaux Mérignac,

5. Cannes Mandelieu,

6. Cazaux,

7. Cherbourg Maupertus,

8. Le Castellet,

9. Istres,

10. Marseille Provence,

11. Montpellier Méditérannée,

12. Nice Côte d'Azur,

13. Paris Vatry,

14. Pau Pyrénées,

15. Tarbes Lourdes Pyrénées,

16. Toulouse Blagnac.

Some airports could appear far from criteria chosen (Nice for traffic for example), but other criteria could compensate the one which is not good for the ranking. This is for this reason that Nice or Marseille have been chosen for example.

If the user wants to study another airport, he just has to enter airport characteristics in the data file and select the airport when he uses the tool.

\section{Traffic data}

Traffic data were essential for the project. The 5 different French en-route control centres provide the data from their databases. Planes are identified by radars of the control centre. Many information is given in the database : position, time, horizontal and vertical speeds, altitude, Flight Level requested, heading, departure and arrival airports, call sign and 
aircraft type. Only the time information is very useful for the study.

\section{Population density data}

For the non-nominal study, the population density was used. To be precise, a mesh built with squares of 200 meters-side-length is used by the tool. The data comes from the INSEE (National Institute for Statistics and Economic Studies).

Same process can be done with other databases of world's countries.

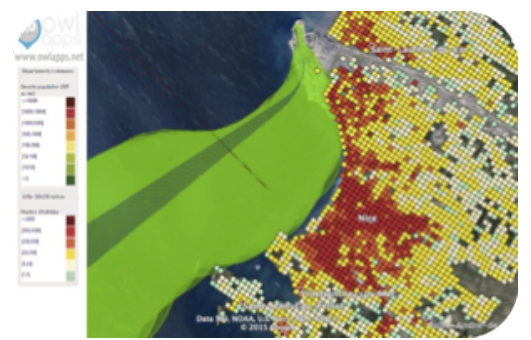

Figure 9 - Visualization of population density through the. $\mathrm{kml}$ file at Nice

\section{TOOL RUNNING}

The tool developed under Matlab code has two big different uses. The first one is an execution of the method, the user just have to select a space plane and the tool will run to rank best airports for this space plane. For the second aspect, the tool is used to check a specific criterion. The user can choose an airport and a space plane, then he has the possibility to draw the trajectory, to find a trajectory respecting the non nominal criteria or checking the probabilities with a defined trajectory, to analyze traffic flow in the airport area, technical characteristics or weather conditions.

Output files are created when the method is used. Two different types of files are made. Excel files are created for stored data : flight parameters, non nominal detailed information and traffic data representing crossing airplanes.

The other kind of files is the. $\mathrm{kml}$ one. These files can be opened with a GIS software and specially Google Earth to visualize the results of the study. Three different things can be shown in Google Earth. The first one is the trajectory for both QFUs, then the S area can be visualized in green and the last thing is for the ground safety study, the no-cross zone is drawn around the runway.

\section{CASE STUDY - Montpellier's Airport}

The aim of the case study is to show how the method runs through the tool developed. It can show the limits of the method.

\section{$\underline{\text { X.I Airport global situation }}$}

Montpellier is located in the Mediterranean coast. This is a touristic area with warm and sunny weather. For space, it is a dynamic region where space school and previous studies on possible space launch site building took place. The choice of Montpellier has been made because it is a quite good place to operate suborbital flights. Furthermore, Montpellier was already studied for suborbital operations by the co-author and other members of the 3AF (Association Aéronautique \& Astronautique de France).

\section{$\underline{\text { X.II Checking airport characteristics }}$}

Each airplane has its own performances for take-off and landing. This preliminary study just checks if the needed distance is available or not at the airport.

- For the horizontal take-off planes, the needed distance is $2600 \mathrm{~m}$ (blue distance on Figure 24).

- For air-dropped space planes (in fact their carryplanes), the needed distance is $3000 \mathrm{~m}$. (red distance on Figure 10).

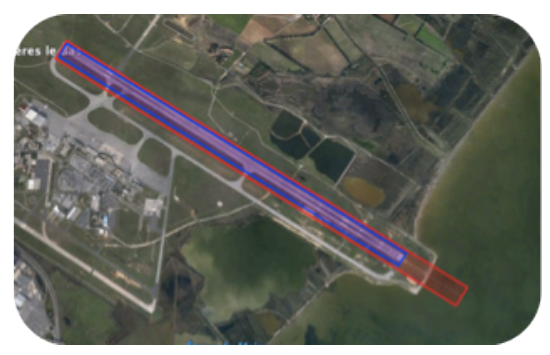

Figure 10 - Runway's distances

At Montpellier, the available distance is $2600 \mathrm{~m}$. That gives us a grade of $100 \%$ for the horizontal take-off spaceplane and $73,4 \%$ for air-launched spaceplane. In addition, the type of runway is significant. For Montpellier, it is an asphalt runway. The coefficient for the grade will be 0,75 for LOXuse on an asphalt runway versus 1 for a concrete runway. This coefficient gives the grade of $75 \%$ for horizontal-take-off space planes and remains 73,4\% for air-dropped ones.

\section{X.III Finding a trajectory}

The first task to perform is to find a nominal trajectory that will be accepted in case of non nominal event for each kind of space plane. 
Regarding horizontal take-off space plane and before running the simulation, the QFU 12L is logically the best one to use in term of ground safety, due to the presence of the sea. The tool helps to determine if the maximum average $\mathrm{N}_{R}$ for safety ground will be reached or not. In the other direction, there is the city of Montpellier. It seems to be difficult to find a trajectory acceptable. For dropped-space plane, the coast is close enough to the runway to drop the plane above the sea, reaching anybody in case of non-nominal event. The dropping point is close enough if a failure ignition happens and then the space plane can reach Montpellier, gliding.

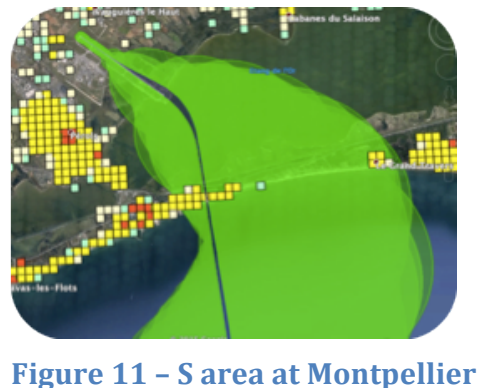

The QFU 12L is first analyzed. To start with, a trajectory is computed right in the direction of the runway, no turn added. Rapidly, the tool performs iterative turns to avoid the dense area of la Graudu-Roi. This trajectory is acceptable for QFU 12L (Figure 11). For the QFU 30R, the idea was to come back as early as possible to fly over the sea. A $230^{\circ}$ turn has been created to the right, to avoid Montpellier. The city of Mauguio was well avoided but then some cities remained in the $\mathrm{S}$ area. Nevertheless, with the same process as before, the average $\mathrm{N}_{R}$ was computed and accepted at the limit for this trajectory.

\section{X.IV Analyzing air \& ground traffic}

Now, trajectories are defined. Traffic analysis can start. A volume is created around the space plane to include debris dispersion in case of explosion. This volume is $19 \mathrm{~km}$ wide, $100 \mathrm{~km}$ long and has a height of $100 \mathrm{~km} .112$ planes had been found in this area for one day. No slot of 25 minutes has been found too. The Air traffic airport grade is $60 \%$. For the ground traffic, there are 15557 movements per year (for the year 2014). The ground traffic grade is $90 \%$. The global traffic grade is $75 \%$.

\section{X.V Weather conditions}

For the wind study, there are 3 major directions for the wind : both in the runway axis and the last one is in the North-North-East direction, which is in crosswind direction. This direction is the major one from November to February, during $32 \%$ of the time up to 17 knots. The grade of $49,8 \%$ is obtained. For the sunshine level, there are 2668 hours of sunshine per year (national average of 1664 hours/year), equivalent of 222 sunny days. The sunshine grade is $87,4 \%$. The last criterion is rain, and the average mean is about $578 \mathrm{~mm} /$ year against $652 \mathrm{~mm} /$ year for the French mean. It must be underlined that huge thunderstorms increase this figures. (cf. flooding in Hérault region). The rain grade is equals to $83,4 \%$. The global weather grade is $80,6 \%$, which ranks the airport in $6^{\text {th }}$ position for the weather conditions.

\section{$\underline{\text { X.VI Ground safety }}$}

The tool draws the exclusion zone in Google Earth. Then, the analysis must be done manually. The exclusion zone is shown in Figure 12. On the threshold 12L (extreme left circle) the distance is not respected with the road and the house.

The road must be closed when the space plane is on the extremity of the runway and habitants have to be considered protected inside the house.Trails located in the North-East of the runway should be closed. Except that, everything is fine for Montpellier ground safety study. Planes must not be on the taxiway when suborbital operations start.

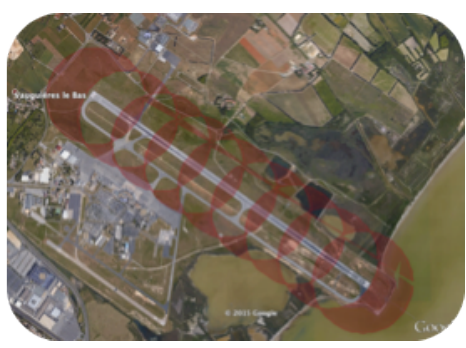

Figure 12 - Exclusion zone

\section{X.VII Conclusion}

The Montpellier's airport is a quite good place for suborbital operations. The traffic is not so dense and particularly on the ground. The weather conditions are excellent with a warm and sunny weather, but sometimes windy. The runway is long enough for horizontal take-off space planes but should be increased by 400 metres for dropped ones. The ground safety is not so bad, but can be improved by doing small works. Montpellier is quite ready to welcome suborbital operations.

\section{LIMITATIONS AND IMPROVEMENTS}

As mentioned in the beginning of this paper, the method and the tool developed for it have been made to do a pre-selection of airports. It is a global 
approach taking into account many criteria. The first limitation, if it is one, is the fact that it is not a study which can be used for operational approvals. Nevertheless, some suborbital consequences have too be studied also : propellants storage, noise study, pollution forecast for example.

\section{Method}

Lacking criteria should be integrated in the next version of the study. Environmental aspects are very relevant nowadays and they are burning issues for the society.

The Non-Nominal part has to be more precise. This is the part that should be improved the most. Statistical approach must be used for debris dispersion. The computation method should be reviewed too: the fact that people are inside a building or not is not taken into account.

The second big work is to improve aerodynamic model. The idea is to create directly the trajectory in 3D. It allows multi-turn trajectory and the turn consequences (decrease of apogee altitude) can be quantified. The re-entry part of the trajectory should be studied deeper and integrated in the tool.

Weather part can be improved with more precise data. The idea is to determine number of slots usable to operate per day.

\section{Tool}

The tool is operational and works well. The functions defined at the beginning of the internship have been created and compute well things established as objectives. The main problem of the tool is its speed performances, it is very slow. To solve the problem, many parts of the tool (maybe all) should be written in an other language (C, Fortran). Nevertheless, the huge databases used for computations and the need to have an interface with the user lead to the fact that using an other language could be the best idea.

\section{DISCUSSION}

The goal was to prove that suborbital operations can be suited in France. Of course, it is easier to build a dedicated platform in the middle of the desert to welcome suborbital activities and if something happens, there is no risk for reaching people on the ground. Does it mean that a space plane will never take-off from France ? From
Europe ? No. Europeans are late but the things are moving and quite rapidly, regarding the UK for example. French administration is known to be slow, but "Destination Etoiles" and "Cosmica Spacelines" are stepping on the gas.

Some airports are well-designed to fit with suborbital activities. The runways are long enough and the traffic not so dense. Suborbital flights can boost the airport development and attract people in the area.

To respect the confidentiality of results, airports are designated by a random letter. Following rankings have been made.

\begin{tabular}{|c|c|c|c|c|c|}
\hline Airport & $\begin{array}{c}\text { H } \\
\text { T/O }\end{array}$ & WEATH & TRAF & NN & GRND \\
\hline A & $\mathbf{1}^{\text {st }}$ & $3^{\text {rd }}$ & $5^{\text {th }}$ & $2^{\text {nd }}$ & $4^{\text {th }}$ \\
\hline B & $\mathbf{2}^{\text {nd }}$ & $1^{\text {st }}$ & $9^{\text {th }}$ & $5^{\text {th }}$ & $1^{\text {st }}$ \\
\hline C & $\mathbf{3}^{\text {rd }}$ & $6^{\text {th }}$ & $1^{\text {st }}$ & $7^{\text {th }}$ & $8^{\text {th }}$ \\
\hline D & $\mathbf{4}^{\text {th }}$ & $8^{\text {th }}$ & $5^{\text {th }}$ & $6^{\text {th }}$ & $6^{\text {th }}$ \\
\hline E & $\mathbf{5}^{\text {th }}$ & $9^{\text {th }}$ & $3^{\text {rd }}$ & $3^{\text {rd }}$ & $6^{\text {th }}$ \\
\hline F & $\mathbf{6}^{\text {th }}$ & $4^{\text {th }}$ & $10^{\text {th }}$ & $1^{\text {st }}$ & $1^{\text {st }}$ \\
\hline G & $\mathbf{7}^{\text {th }}$ & $10^{\text {th }}$ & $4^{\text {th }}$ & $4^{\text {th }}$ & $4^{\text {th }}$ \\
\hline H & $\mathbf{8}^{\text {th }}$ & $4^{\text {th }}$ & $8^{\text {th }}$ & $9^{\text {th }}$ & $1^{\text {st }}$ \\
\hline I & $\mathbf{9}^{\text {th }}$ & $1^{\text {st }}$ & $7^{\text {th }}$ & $8^{\text {th }}$ & $9^{\text {th }}$ \\
\hline J & $\mathbf{1 0}^{\text {th }}$ & $7^{\text {th }}$ & $1^{\text {st }}$ & $10^{\text {th }}$ & $10^{\text {th }}$ \\
\hline
\end{tabular}

Figure 13 - Results for autonomous spaceplanes

But suborbital flight cannot just be a gift from the sky. Investments must be done to secure the operations, the users and workers at the airport, the population under the flight path and all the passengers inside commercial aircrafts. The perfect airport does not exist at this time, no one had reached the $100 \%$ grade.

The runway length and type is the easier thing to adapt, most of the time it is just a problem of money. The traffic integration can be solve with the idea proposed just above : shared-activity between airports.

The non-nominal consequences and ground safety are more difficult to make them evolve. This part deals with the regulation evolution : possibility to reduce exclusion zone and new way to compute the risks with a more acceptable criterion. The other solution is to make people move from critical area, which is, I think, quite impossible and more difficult in a country as France.

Other criteria not studied in this report are very relevant and must be analyzed. First of all, there is 
pollution. People are very sensible to environmental issues and the use of LOX or other propellants should be quantified deeply. What are the consequences if a ground LOX (or anything else toxic) tanks breaks into parts? What is the quantity of pollution during initial climb? The noise is the second big aspect. Will local population accept it?

Some places are ready near the Mediterranean Sea to welcome suborbital flights. Technically, it is feasible. Soon, the authors are sure that an individual will reach the edge of space from Europe, making him think that space is so close ; 100 kilometres, it is nothing at the Earth scale. And the proximity is underlined if the launch is made near cities and life, not in a desert where you have already left the every-day's world.

\section{CONCLUSION}

Regulation is a big part of the study. An evolving regulation could change the ranking: lower minimum safety distances or higher threshold for non-nominal part. Technology could also bring some changes regarding grades. The space planes may take-off faster and could use smaller runways or climb better and the no-cross zone becomes smaller, impacting less commercial aircraft. The implementation of basic-airplane engine to let the runway open during suborbital operations could be also a solution.

Suborbital activities are just at their beginning and they will rapidly develop themselves and it has been shown that it is possible in France. The South part of France is inevitably the best one with the Mediterranean Sea, a warm and sunny weather and lots of airports in a touristic region.

The future selected airports to operate suborbital flights will be the most valuable to launch orbital flights. Will the South of France will be connected to New-York in less than one hour?

\section{REFERENCES}

[1] SMITH, G. AND ZERVOS, V., 2010. Legal and Political Approaches to Obtaining Commercial Human Suborbital Spaceflight Launch Authorization from the Airport of Saragossa, Spain; In: L. MORRIS, K. COX, eds. Space Commerce The Inside Story by the People Who are Making it Happen. Aerospace Technology Working Group, 287-312

${ }^{[2]}$ DESVALLEES, P. 24 March 2015, Personal communication.

[3] 16 June 2015, Press Release - U.S. and France Sign Memorandum of Cooperation to Share Commercial Space Transportation Research and Development Activities [online]. Available from: https://www.faa.gov/news/press_releases/news_story.cfm?newsId=19075 [Accessed 23 September 2015]

[4] HATtENBERGER, G, 2012, "Flight Mechanics” ENAC course

${ }^{[5]}$ WIESEL, E. W, 2010, Spaceflight Dynamics

${ }^{[6]}$ BONNAL, C, March-April-May 2015, Personal communication.

[7] 14 CFR Part 431 - Launch And Reentry Of A Reusable Launch Vehicle (RLV) - www.ast.faa.gov 14 CFR Part 420 - License To Operate A Launch Site - www.ast.faa.gov

${ }^{[8]}$ Energy during an explosion, www.fas.org/nuke/intro/effects.html

[9] DGAC, 2014, Annual Traffic Statistics Report

${ }^{\text {[10] }}$ KAMPMIER C, Evaluation of a mitigation procedure for small liquid oxygen (LOX) spills

${ }^{[11]}$ NASA, TM-X-64086 Test of LOX compability for asphalt and concrete runway materials

[12] INSEE, 2010, Population density database, www.insee.fr/fr/themes/detail.asp?reg id=0\&ref id= donnees_carroyees\&page=donnees_detaillees/donnees_carroyees/donnees-carroyees-200m.html 